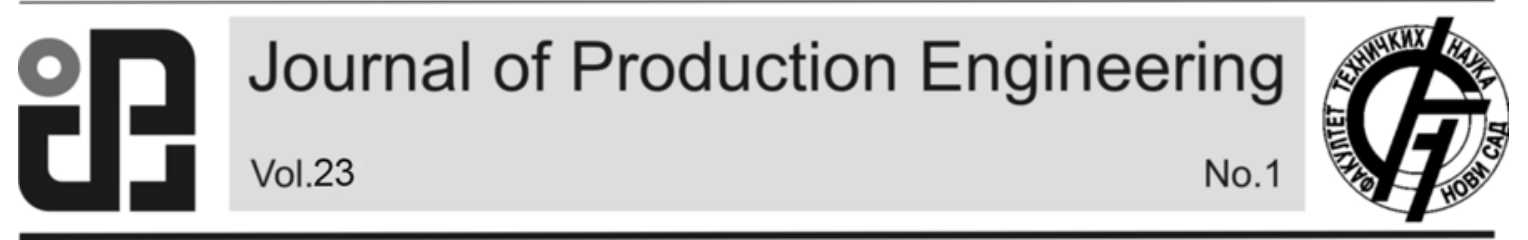

JPE (2020) Vol.23 (1)

Original Scientific Paper

Štrbac, B., Biševac, S., Delić, M., Ačko, B, Havrlišan, S., Hadžistević, M.

\title{
COMPETENCE ASSESSMENT OF CMMS FOR DIFFERENT MEASURING TASKS
}

Received: 22 December 2019 / Accepted: 28 March 2020

\begin{abstract}
In order to check the competence of measurement laboratories, there is a need for laboratories to participate in interlaboratory comparisons. Competence of a laboratory is expressed through En number which compares measurement results and measurement uncertainty of the examined laboratory with measurement results and measurement uncertainty of the reference laboratory. In this research, the design of experiments (DoE) was used for the assessment of measurement uncertainty. Two characteristics of a ring gauge were measured using a coordinate measuring machine (CMM) - diameter and roundness. Experimental investigations were carried out in the Laboratory for Metrology in Novi Sad and the Laboratory for Dimensional Metrology in Maribor, which is the holder of the national standard of the Republic of Slovenia.
\end{abstract}

Key words: Interlaboratory comparison, measurement uncertainty, DoE, CMM.

Ocena kompetentnosti KMM za razlicite merne zadatke. U cilju provere sposobnosti mernih laboratorija postoji potreba da laboratorije učestvuju u međulaboratorijskim poređenjima. Sposobnost laboratorije se iskazuje preko En broja koji poredi rezultate merenja i merne nesigurnosti ispitane laboratorije sa referentnom. U ovom istraživanju korišćen je dizajn eksperimenta za procenu merne nesigurnosti. Merene su dve karakteristike referentnog prstena na koordinatno mernoj mašini - prečnik $i$ kružnost. Eksperimentalna istraživanja su sprovedena u Laboratoriji za metrologiju u Novom Sadu i Laboratoriji za dimenzionalnu metrologiju u Mariboru koja je nosilac nacionalbnog etalona Slovenije.

Ključne reči: Međulaboratorijsko upoređivanje, merna nesigurnost, DoE, CMM.

\section{INTRODUCTION}

Systemic solutions which are acceptable to quality management and the possibility of their certification in compliance with a series of ISO 9000 standards means that numerous metrological laboratories have to face measurement uncertainty, calibration, and metrological traceability. For that purpose, a large number of recommendations and metrological standards are needed. In the field of dimensional metrology coordinate measuring machines (CMMs) have a leading role in verification operations. All macro tolerances stated in the standard of the geometrical product specifications (GPS) can be inspected using CMMs. To guarantee the adequacy of inspection, measurement results have to be validated through a rigorous system of traceability. Every measurement result obtained by means of a CMM has to be stated along with measurement uncertainty, with the aim of providing a satisfactory basis for deciding about compliance with the specification. However, due to the complexity of CMMs and the widespread use of these in different measurements, traceability maintenance and the assessment of measurement uncertainty are quite complicated. Results obtained by means of a CMM can be documented by participating in interlaboratory comparison. In order to assess the performance of different metrological laboratories, from national metrological institutes to market-oriented laboratories, a metrological tool - interlaboratory comparison is used. Interlaboratory comparisons are also very important in proving the quality of measurement when measurement uncertainty is hard to determine [1]. According to ISO/IEC 17043:2010, interlaboratory comparison includes organization, conduction and evaluation of measurements or tests on the same or similar objects performed by two or more laboratories or inspection institutes in accordance with previously defined conditions [2]. In this paper, experimental investigations were carried out according to a defined design of experiments in two metrological laboratories by means of CMMs. Measurement results enabled conducting a study of interlaboratory comparison.

\section{THEORETICAL FRAMEWORK AND SUBJECT OF RESEARCH}

In order to determine the effectiveness of participants in interlaboratory comparison, measurement data are taken from all the participants and assessed by means of the agreed upon statistical approach. Unique measured values reported by participants are compared with the agreed upon reference value, taking into account the reported measurement uncertainties and the uncertainty of the reference value. En number represents the factor of agreement between results and is calculated with the aim of assessing the compatibility of measurement results of laboratories taking part in the comparison with the reference result. En number is used in comparisons in which participating laboratories report measurement uncertainty in accordance with the Guide to the expression of uncertainty in measurement (GUM). When uncertainty is assessed in accordance with GUM, En number expresses the validity of the 
assessment of expanded uncertainty which accompanies every measurement result. The condition $|E n|<1$ shows that measurements conducted in the examined laboratory are compatible with the reference laboratory, i.e. the more the value of $E n$ approaches zero, the higher the compatibility of the result. En number is calculated using the expression (1):

$$
E_{n}=\frac{x_{l a b}-x_{r e f}}{\sqrt{U_{l a b}^{2}-U_{r e f}^{2}}}
$$

$x_{l a b}-$ measurement result of participating laboratotry, $x_{r e f}$ - measurement result of reference laboratory,

$U_{l a b}$ - expanded uncertainty of participating laboratory, $U_{\text {ref }}$ - expanded uncertainty of reference laboratory.

It is clear from the expression (1) that it is necessary to determine the expanded uncertainty of CMM measurements in order to perform successful interlaboratory comparison. In assessing measurement uncertainty of CMM measurements, various factors affecting measurement uncertainty need to be considered. Factors affecting measurement uncertainty can be classified into five categories: CMM hardware, work environment, workpiece, sampling strategy and evaluation strategy. It is not possible to include all influential factors in the assessment of measurement uncertainty in the currently used assessment methods [3]. The Guide to the expression of uncertainty in measurement (GUM) can be used although it is limited to a great extent. Over the past two decades a lot of effort has been made in the field of assessing measurement uncertainty in CMMs. What is more, every measuring task has a different measurement uncertainty with the same CMM. Therefore, the concept of "task specific uncertainty" has been introduced into literature. The result of continuous research in this field over many years is the introduction of standard methods within ISO 15530:2008, implying the use of calibrated workpieces - ISO 15530 - 3 and computer simulation ISO 15530 - 4. The use of the design of experiments (DoE) makes it possible to include a number of factors and determine the effect of every factor and their interactions on measurement uncertainty [4,5]. By means of repeated measurements, standard deviation is expressed for each observation, representing the basis for expressing measurement uncertainty which is calculated using the expression (2) [6]:

$$
U=k \times \sqrt{u_{c a l}^{2}+u_{p r o c}^{2}+u_{\Delta T}^{2}}
$$

$U$ - expanded measurement uncertainty,

$k$ - coverage factor,

$u_{c a l}$ - standard calibration uncertainty of the measured object,

$u_{\text {proc }}$ - standard uncertainty of measurement procedure,

\begin{tabular}{|c|c|c|c|}
\hline Factor & \multicolumn{2}{|c|}{ Level } & Code \\
\hline $\begin{array}{c}\text { Position of workpiece } \\
\text { on CMM table }\end{array}$ & 1 & 3 & A \\
\hline Alignment & CMM & Workpiece & $\mathrm{B}$ \\
\hline Stylus tip diameter & $5 \mathrm{~mm}$ & $15 \mathrm{~mm}$ & $\mathrm{C}$ \\
\hline Sampling size & 15 & 150 & $\mathrm{D}$ \\
\hline
\end{tabular}
$u_{\Delta T}-$ standard uncertainty of the effect of temperature.

Table1. Analyzed factors and levels

\subsection{Design of experiments}

The design of experiments is used in numerous applications to help understand a certain process or variable. In order to include the most influential factors which affect measurement uncertainty in measuring the characteristics of holes by means of CMMs, the following factors and their corresponding levels were considered (Table 1).

The factor "position of workpiece on CMM table" includes the effect of hardware errors on measurement uncertainty: random and systematic errors of the probe and geometric errors of the CMM. This factor is present on four levels, i.e. the workpiece was positioned in the corners of the table. The "alignment" factor considers the assessment of the workpiece features if the coordinate system for the sampled points is positioned in a different way. This way evaluation strategy was taken into account. The factor "stylus tip diameter" introduces mechanical filtration for sampling deviations from the workpiece. This factor is particularly important when measuring roundness because it filters out the effect of roughness and waviness on the form error . The factor "sampling size" refers to the number of points which describe real geometry (Fig. 1). Interacting with form deviation of a workpiece and the applied evaluation algorithm, it can affect the measurement result to a great extent (measurement uncertainty) when assessing form deviation [7].

\section{EXPERIMENTAL INVESTIGATIONS}

With the aim of making interlaboratory comparisons, a ring gauge with the diameter of $\mathrm{D}=60 \mathrm{~mm}$ was measured according to the previously described design of experiments in the Laboratory for Metrology, Novi Sad (CMM Carl Zeiss Contura g2 RDS, $\left.\mathrm{MPE}_{\mathrm{E}}=1.9+\mathrm{L} / 330 \mu \mathrm{m}\right)$ and in the Laboratory for Dimensional Metrology, Maribor (CMM Carl Zeiss UMS 850, $\left.\mathrm{MPE}_{\mathrm{E}}=2.1+\mathrm{L} / 300 \mu \mathrm{m}\right)$. Two features of the ring gauge were analyzed: diameter and roundness. Each observation had five replicates so that the total number of experiments in one laboratory was 160 . The experiment was completely randomized. As the Laboratory for Dimensional Metrology is the holder of the national standard in Slovenia, reference values for the diameter, roundness were determined in this laboratory, as well as the values of standard uncertainty of calibration of the measured object $u_{\text {cal }}$. Meaurements were taken in temperature controlled laboratories.
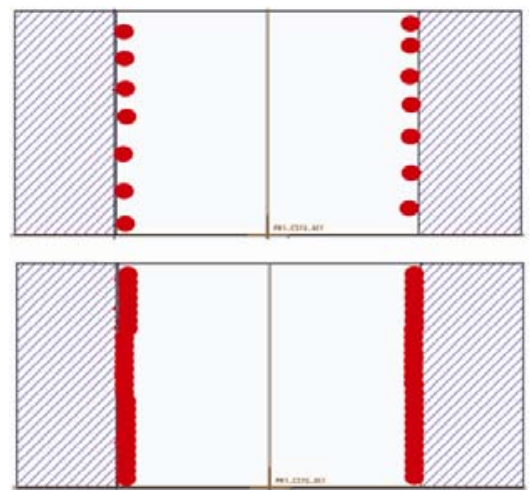

Fig. 1. Factor ,sampling size“ 


\subsection{Results of the experiments and uncertainty assessment}

Statistical analysis of the measured results was performed using Minitab 17 software. Based on the variance analysis (ANOVA) with the significance level of $\alpha=0.05$, it was determined which factors and factor interactions were significant for the diameter and roundness of the ring gauge in the experiments conducted in the two laboratories (Table 2).

Additionally, Table 2 presents the levels of factors where the deviation of values of the observed characteristics from the reference value is the smallest and the largest. Standard deviation is used as a measure of measurement uncertainty (type A uncertainty) and is calculated for each combination of factors based on five replicates. The combinations of factors with the smallest and the largest standard deviation for the observed characteristics are given in Table 3 . It can be seen in Table 3 that the values of standard deviations vary enormously with different values of levels of factors.

\begin{tabular}{|c|c|c|c|c|}
\hline & Diameter_Maribor & Roundness_Maribor & $\begin{array}{c}\text { Diameter_Novi } \\
\text { Sad }\end{array}$ & Roundness_Novi Sad \\
\hline $\begin{array}{l}\text { Statistically } \\
\text { significant } \\
\text { parameters }\end{array}$ & $\begin{array}{l}\mathrm{A}, \mathrm{C}, \mathrm{D}, \mathrm{A} * \mathrm{~B}, \mathrm{~A} * \mathrm{C}, \\
\mathrm{A}^{*} \mathrm{D}, \mathrm{A} * \mathrm{~B}^{*} \mathrm{C}, \\
\mathrm{A}^{*} \mathrm{C}{ }^{*} \mathrm{D}\end{array}$ & $\mathrm{A}, \mathrm{D}, \mathrm{A}^{*} \mathrm{D}$ & $\begin{array}{l}\mathrm{A}, \mathrm{C}, \mathrm{D}, \quad \mathrm{A}^{*} \mathrm{~B}, \\
\mathrm{~A}^{*} \mathrm{C}, \mathrm{A}^{*} \mathrm{D}, \mathrm{B}^{*} \mathrm{C},\end{array}$ & $\begin{array}{l}A, C, D, A^{*} C, A^{*} D \\
B^{*} D, C * D, A^{*} B^{*} C, \\
A^{*} C^{*} D\end{array}$ \\
\hline $\begin{array}{l}\text { Levels of factors } \\
\text { with smallest } \\
\text { deviation from } \\
\text { reference value }\end{array}$ & $\begin{array}{lr}\text { Variable } & \text { Setting } \\
\text { A } & \mathbf{4} \\
\text { B } & \text { Workpiece } \\
\text { C } & 5 \\
\text { D } & 15 \\
\end{array}$ & $\begin{array}{lr}\text { Variable } & \text { Setting } \\
\text { A } & \mathbf{3} \\
\text { B } & \text { Workpiece } \\
\text { C } & \mathbf{5} \\
\text { D } & 15 \\
\end{array}$ & $\begin{array}{lr}\text { Variable } & \text { Setting } \\
\text { A } & 1 \\
\text { B } & \text { Workpiece } \\
\text { C } & \mathbf{1 5} \\
\text { D } & 15 \\
\end{array}$ & $\begin{array}{lc}\text { Variable } & \text { Setting } \\
\text { A } & \mathbf{3} \\
\text { B } & \text { CMM } \\
\text { C } & \mathbf{1 5} \\
\text { D } & \mathbf{1 5} \\
\end{array}$ \\
\hline $\begin{array}{l}\text { Levels of factors } \\
\text { with greatest } \\
\text { deviation from } \\
\text { reference value }\end{array}$ & $\begin{array}{lr}\text { Variable } & \text { Setting } \\
\text { A } & \mathbf{3} \\
\text { B } & \text { Workpiece } \\
\text { C } & \mathbf{5} \\
\text { D } & \mathbf{1 5 0} \\
\end{array}$ & $\begin{array}{lr}\text { Variable } & \text { Setting } \\
\text { A } & \mathbf{1} \\
\text { B } & \text { Workpiece } \\
\text { C } & \mathbf{5} \\
\text { D } & \mathbf{1 5 0} \\
\end{array}$ & $\begin{array}{lc}\text { Variable } & \text { Setting } \\
\text { A } & \mathbf{1} \\
\text { B } & \text { CMM } \\
\text { C } & \mathbf{5} \\
\text { D } & \mathbf{1 5} \\
\end{array}$ & $\begin{array}{l}\text { Variable } \\
\text { A } \\
\text { B } \\
\text { C } \\
\text { D } \\
\end{array}$ \\
\hline
\end{tabular}

Table 2. Significance of factors and levels of factors with largest and smallest deviation

\begin{tabular}{|cllccc}
\hline \multirow{2}{*}{ Characteristic } & Standard deviation & \multicolumn{4}{c}{ Levels of factors } \\
& A & B & C & D \\
Dia_Maribor & $\max =0.9094 \mu \mathrm{m}$ & 4 & CMM & 5 & 150 \\
& $\min =0.0002 \mu \mathrm{m}$ & 2 & Workpiece & 5 & 150 \\
\multirow{3}{*}{ Round_Maribor } & $\max =0.6955 \mu \mathrm{m}$ & 4 & CMM & 5 & 150 \\
& $\min =0.0102$ & 3 & CMM & 15 & 150 \\
\multirow{2}{*}{ Dia_Novi Sad } & $\max =0.5273 \mu \mathrm{m}$ & 3 & CMM & 5 & 150 \\
& $\min =0.001 \mu \mathrm{m}$ & 1 & CMM & 5 & 15 \\
Round_Novi Sad & $\max =3.668 \mu \mathrm{m}$ & 2 & Workpiece & 5 & 15 \\
& $\min =0.0001 \mu \mathrm{m}$ & 4 & Workpiece & 15 & 150
\end{tabular}

Table 3. Combinations of factors with the smallest and the largest standard deviation for the observed characteristics

Comparing the levels of factors from Table 2 and Table 3, it can be concluded that the levels of factors which give the smallest deviation from the reference value (measurement error) are not the same levels which show the smallest standard deviation as a measure of measurement uncertainty. Likewise, the considered factors are not on the same level if we observe the smallest measurement error or the smallest standard deviation for different characteristics, such as diameter and roundness in this case. This confirms that the assessment of measurement uncertainty in coordinate measuring is very complex and that every measuring task has different measurement uncertainty which is the result of a number of factors all of which cannot be analyzed. Expanded measurement uncertainty is calculated using the expression (2), whereas the standard uncertainty of measurement procedure is calculated using the expression (3):

$$
u_{\text {proc }}=\sqrt{\frac{M P E_{E}{ }^{2}}{a}+u_{\text {rep }}^{2}}
$$

where $M P E_{E} / \mathrm{a}$ is the maximum permissible error with the applied adequate distribution function (e.g. rectangular) and $u_{\text {rep }}$ denotes reproducibility of measurement obtained through repeated measurements. As presented in Table 3, the value of $u_{\text {rep }}$ varies from the smallest to the greatest value. However, it was the average value of all standard deviations for all experiments that was taken to calculate the expanded measurement uncertainty $U$. The values of the expanded uncertainties are presented in Table 4.

\begin{tabular}{|c|c|}
\cline { 2 - 2 } \multicolumn{1}{c|}{} & Expanded uncertainty U $[\mu \mathrm{m}]$ \\
\hline Dia_Maribor & 0,272 \\
\hline Round_Maribor & 0,263 \\
\hline Dia_Novi Sad & 0,351 \\
\hline Round_Novi Sad & 0,989 \\
\hline
\end{tabular}

Table 4. Values of expanded uncertainties

\section{INTERLABORATORY COMPARISON}

Compatibility of the participating laboratory with the reference laboratory was determined using the expression (1) and the results were the following: 


$$
\begin{aligned}
& E_{n(\text { Dia })}=\frac{x_{\text {lab }}-x_{r e f}}{\sqrt{U_{\text {lab }}^{2}-U_{r e f}^{2}}}=\frac{60,0017-60,0012}{\sqrt{0.000351^{2}-0.000272^{2}}}=2.25 \\
& E_{n(\text { Round })}=\frac{x_{\text {lab }}-x_{r e f}}{\sqrt{U_{\text {lab }}^{2}-U_{r e f}^{2}}}=\frac{0.002072-0.001372}{\sqrt{0.00098^{2}-0.000263^{2}}}=0.74
\end{aligned}
$$

The results show that the examined laboratory is compatible in the case of measuring roundness, whereas it is incompatible in the case of measuring diameter. This statement is somewhat surprising because the
CMM in Novi Sad has a smaller specified maximum permissible error. The reason for this lies in the increase in geometric errors of the CMM in question. Likewise, measurement error and the error of the assessed measurement uncertainty for both metrological tasks were greater in Novi Sad laboratory. Fig. 2 is a graphical representation of comparison of measurement error and measurement uncertainty when measuring diameter.

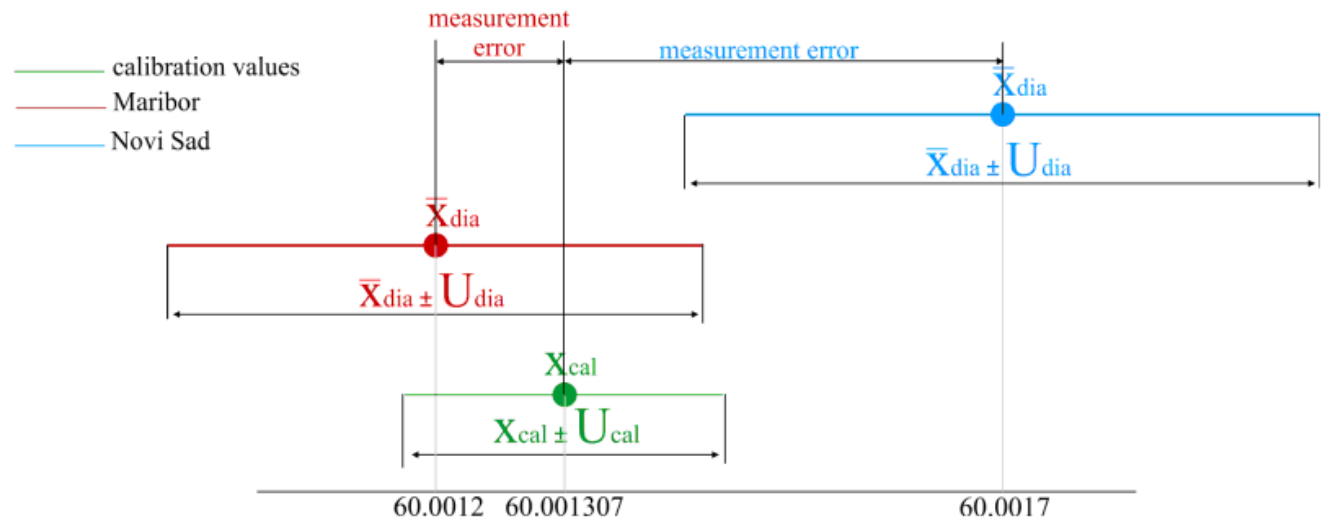

Fig. 2. Graphical representation of interlaboratory comparison

\section{CONCLUSION}

This paper presents interlaboratory comparison between two metrological laboratories with the aim of determining the capability of CMMs to perform different tasks of measurement and control. It was necessary to assess measurement uncertainty of a specific measuring task in order to make the comparison. The use of the design of experiments was thoroughly described. The conducted study, focusing on two characteristics of a ring gauge (diameter and roundness), showed different scenarios of the effect of factors on measurement error and measurement uncertainty, both for different characteristics and different CMMs. Future studies will incorporate temperature into the design of experiments since this factor has a significant effect on measurement error and measurement uncertainty.

\section{REFERENCES}

[1] Acko, B., Brezovnik, S., Crepinsek Lipus, L., Klobucar, R: Verification of statistical calculations in interlaboratory comparisons by simulating input datasets, International journal of Simulation Modeling, Vol. 14 (2), pp. 227-237, 2015.

[2] ISO/IEC Guide 43-1:2008: Proficiency testing by Interlaboratory comparison, Part 1: Development and operation of proficiency testing schemes" ISO/CASCO Committee on conformity assessment, 2008.

[3] Štrbac, B., Radlovački, V., Spasić - Jokić, V., Delić, M. Hadžistević, M.: The difference between GUM and ISO/TC 15530-3 method to evaluate the measurement uncertainty of flatness by a CMM, Journal of Metrology Society of India, Vol. 32(4), pp. 251-257, 2017.

[4] Vrba, I., Palenčar, R., Hadžistević, M., Štrbac, B.,
Spasić - Jokić, V., Hodolič, J.: Different Approaches in Uncertainty Evaluation for Measurement of Complex Surfaces Using Coordinate Measuring Machine, Measurement Science Review, Vol. 15(3), pp. 111-118, 2015.

[5] Štrbac, B., Ačko, B., Havrlišan, S., Matin, I., Savković, B., Hadžistević, M.: Investigation of the Effect of Temperature and Other Significant Factors on Systematic Error and Measurement Uncertainty in CMM Measurements by Applying Design of Experiments, Measurement, Vol. 158, 2020.

[6] Barini, E.M., Tosello, G., De Chiffre, L.: Uncertainty analysis of point-by-point sampling complex surfaces using touch probe CMMs: DOE for complex surfaces verification with CMM, Precision Engineering, Vol. 34(1), pp. 16-21, 2010.

[7] Hadžistević, M., Štrbac, B., Spasić Jokić, V., Delić, M. Sekulić, M., Hodolič, J.: Fastors of estimating flatness error as a surface requirement of exploitation, Metallurgy, Vol. 54(1), pp. 239-242, 2015.

Assist. Prof Branko Strbac, MSc Sonja Bisevac, Full Prof. Miodrag Hadzistevic, University of Novi Sad, Faculty of Technical Sciences, Department of Production Engineering, Trg Dositeja Obradovica 6, 21000 Novi Sad, Serbia. e-mail: $\quad$ strbacb@uns.ac.rs, sonja.bisevac@hotmail.com, miodrags@uns.ac.rs.

Assoc. Prof. Milan Delić, University of Novi Sad, Faculty of Technical Sciences, Department of Industrial Engineering and Engineering Management, Trg Dositeja Obradovica 6, 21000 Novi Sad, Serbia. e-mail: delic@uns.ac.rs

Full Prof. Bojan Acko, University of Maribor, Faculty of Mechanical Engineering, Chair of Production Engineering, Smetanova ul.17, 2000 Maribor. e-mail:bojan.acko@um.si, PhD Sara Havrlišan, Josip Juraj Strossmayer University of Osijek, Mechanical Engineering Faculty, 35000 Slavonski Brod, Croatia, Phone: +385 35446 188, Fax: +385 35446 446, e-mail: shavrlisan@sfsb.hr 